\title{
Informasi Akuntansi Lingkungan: Apa yang Memotivasi Perusahaan untuk Mengungkapkan?
}

\author{
Friendty $^{1}$, Anita $^{2}$ \\ Universitas Internasional Batam ${ }^{1,2}$ \\ $\underline{\text { 1842120.friendty@uib.edu }}{ }^{1}, \underline{\text { anita.lec@uib.ac.id }}{ }^{2}$
}

*Corresponding Author

Diajukan : 14 Nopember 2021

Disetujjui $\quad: 7$ Desember 2021

Dipublikasi : 2 Januari 2022

\begin{abstract}
Over the years, there has been an increase in corporate initiatives in the area of environmental reporting practices. The study is conducted to analyze the factors that influence the disclosure of environmental accounting in companies in Indonesia. The sample in this study are 44 entities listed on the IDX from 2016-2020 which are collected by purposive sampling method. The data analysis technique used is panel data regression which is tested with SPSS and Eviews. The results show that firm size, auditor independence and public ownership do not affect environmental disclosure. Profitability affects environmental disclosure negatively. Leverage, listing period and company reputation positively affect environmental disclosure.
\end{abstract}

Keywords: Auditor Independence; Company Reputation; Company Size; Environmental Accounting Disclosures; Leverage; Listing Period; Profitability; Public Ownership

\section{PENDAHULUAN}

Dulu, kebanyakan perusahaan beranggapan bahwa tanggung jawab perusahaan hanyalah sebatas pada pengungkapan laporan kinerja keuangan sehingga tidak memberikan perhatian kepada pengungkapan masalah sosial dan lingkungan. Namun, seiring perkembangan zaman hal ini pun berubah, para pemegang saham dan juga pemangku kepentingan lainnya menyadari bahwa isu atau masalah ini akhirnya akan mempengaruhi keberlanjutan jangka panjang perusahaan secara keseluruhan (Amosh \& Mansor, 2018). Kelestarian lingkungan merupakan isu krusial bagi banyak negara terutama Indonesia yang memiliki ketergantungan pada eksploitasi sumber daya alam dalam menjalankan perekonomian negaranya (Angela \& Handoyo, 2021).

Data Kementerian Lingkungan Hidup dan Kehutanan (KLHK) menunjukkan bahwa pada bulan Juni 2019-Juli 2020 terjadi kehilangan hutan bruto sebesar 119.000 hektare. Selain itu, ada beberapa kasus seperti pada PT Indah Kiat Pulp and Paper Tbk yang dari aktivitasnya menyebabkan adanya pencemaran serta kerusakan pada lingkungan sekitar perusahaan beroperasi (Walhi, 2017). Kemudian, adanya aksi protes warga pada PT Toba Pulp Lestari Tbk sejak 2017 hingga saat ini yang dari aktivitas usahanya telah mengakibatkan pencemaran dan kerusakan hutan di daerah Danau Toba, Sumatera Utara (Karokaro, 2021). Dari kasus-kasus ini, menunjukkan bahwa perusahaan tidak mementingkan kepentingan bersama dan hanya mempedulikan keuntungan yang diterima perusahaan. Hal ini menyebabkan semakin banyak permasalsaahan pada lingkungan kita dan memberikan efek yang berkelanjutan.

Cara-cara perusahaan mengurangi dampak buruk terhadap lingkungan perlu dijelaskan dalam laporan keuangan yang disebut dengan pengungkapan akuntansi lingkungan (Nisa, 2017). Akuntansi dan informasi pendapatan serta biaya lingkungan akan membantu perusahaan memahami dengan jelas hubungan antara kegiatan bisnis dan lingkungan. Selain itu, akan meningkatkan prestise dan citra bisnis dengan mitra dalam dan luar negeri (T. M. H. Nguyen et al., 2020). Setelah perusahaan menyadari kepedulian lingkungan merupakan bagian yang tidak 
terpisahkan dari tugasnya, praktik akuntansi lingkungan dapat dilakukan tanpa menunggu tekanan dari pemangku kepentingan (Suryani \& Rofida, 2020).

Beberapa penelitian dahulu seperti Blessed et al. (2019), Soa et al. (2018) dan Aryanti dan Aryani (2020) telah meneliti faktor yang mempengaruhi pengungkapan lingkungan. Ukuran perusahaan membawa pengaruh potensial terhadap jumlah pengungkapan lingkungan di negaranegara berkembang (Bidari \& Djajadikerta, 2020). Tekanan akan tanggung jawab sosial akan selalu ada pada perusahaan besar (Riantani \& Nurzamzam, 2015). Menurut teori pemangku kepentingan, semakin besar profitabilitas perusahaan maka perusahaan semakin ambisius untuk bertanggung jawab kepada pemangku kepentingan atas pengungkapan lingkungan (Soa et al., 2018). Berbeda dengan Yusoff et al. (2018) dan Ijma et al. (2018) yang mengemukakan bahwa profitabilitas tidak akan menjadi dasar perusahaan untuk melakukan pengungkapan informasi lingkungan jika perusahaan memiliki rasa tanggung jawab yang kuat pada lingkungan. Selain itu, berdasar teori keagenan, perusahaan yang memiliki nilai leverage tinggi akan cenderung melakukan pengungkapan (Juhmani, 2014). Sedangkan, menurut Soa et al. (2018) perusahaan yang memiliki utang tinggi sering dihadapi dengan masalah keuangan sehingga sulit untuk mengeluarkan biaya untuk mengungkapkan informasi. Perusahaan dengan umur lebih tua juga dikatakan lebih relatif untuk berpartisipasi dan melaporkan praktik sosial dan lingkungan karena biaya yang dikeluarkan dianggap lebih murah daripada perusahaan kecil (L. S. Nguyen et al., 2017).

Auditor independen juga dipandang sebagai ukuran yang berkontribusi pada penyelesaian pengungkapan akuntansi lingkungan di perusahaan (L. S. Nguyen et al., 2017). Selain itu, dengan adanya kepemilikan publik akan semakin menuntut perusahaan untuk lebih banyak mengungkapkan informasi perusahaan. Tuntutan tersebut juga berkaitan dengan kepercayaan pemegang saham terhadap kinerja perusahaan (Suhartono et al., 2018). Menurut Welbeck et al. (2017), salah satu faktor yang juga dapat membuat perusahaan melakukan pengungkapan lingkungan adalah tekanan pemangku kepentingan yang memaksa perusahaan untuk menjaga reputasi perusahaan sehingga perusahaan akan lebih melakukan pengungkapan lingkungan.

Karakteristik perusahaan sering dikaitkan dengan kualitas informasi keuangan tetapi kurang memperhatikan informasi non-keuangan seperti kualitas informasi lingkungan (Ismail \& Rahman, 2016). Sehingga, pemahaman mengenai faktor yang menentukan kualitas keterbukaan informasi lingkungan relevan untuk dilakukan (Angela \& Handoyo, 2021). Dengan melakukan pengungkapan yang banyak tentang lingkungan tidak berarti kualitas yang dilaporkan perusahaan juga akan baik (Baalouch et al., 2019; Wut \& Ip, 2021). Studi sebelumnya tentang pengungkapan lingkungan sebagian besar dilakukan dengan memfokuskan pada kuantitas pengungkapan tanpa begitu memperdulikan kualitas pengungkapan (Ekundayo \& Josiah, 2020; Ismail \& Rahman, 2016; Michelon et al., 2015; Palisetti, 2020). Dengan sifat pelaporan CSR yang dilakukan secara sukarela, praktik pelaporan CSR juga perlu dianalisis isi pengungkapan untuk mendeteksi kemungkinan penyalahgunaannya. Hal ini penting untuk diperhatikan karena pemangku kepentingan harus memperoleh informasi yang kredibel dari laporan CSR perusahaan meskipun pengungkapannya bersifat sukarela (Anugerah et al., 2019). Terdapat kelemahan yang nyata dalam analisis isi dengan menggunakan metode item checklist tanpa analisis lebih lanjut, yaitu kurangnya pemahaman tentang kualitas pengungkapan informasi secara kompleks (Michelon et al., 2015). Selain itu, di daerah Asia sendiri riset mengenai laporan keberlanjutan masih sangat sedikit dan kebanyakan hanya ditemukan penelitian yang dilakukan pada negara maju dan masih sangat sedikit ditemukan penelitian di negara berkembang seperti di Indonesia (Amidjaya \& Widagdo, 2020; Bae et al., 2018; Meutia et al., 2021; Saha \& Akter, 2013).

Studi ini mencoba untuk mengisi kesenjangan dalam literatur dengan memeriksa kualitas pengungkapan lingkungan perusahaan (daripada kuantitasnya) dan memilih perusahaan di Indonesia untuk menjadi objek penelitian. Studi menggunakan analisis isi dengan metode scoring untuk menyelidiki secara komprehensif pengungkapan lingkungan dalam laporan keberlanjutan yang telah diterbitkan perusahaan. Penelitian ini bertujuan untuk mengetahui faktor-faktor yang 
mempengaruhi pengungkapan informasi akuntansi lingkungan pada perusahaan yang terdaftar di Bursa Efek Indonesia (BEI).

\section{Teori Legitimasi}

\section{STUDI LITERATUR}

Teori legitimasi dapat diartikan sebagai suatu kerangka konseptual yang didasari atas hubungan sosial serta hubungan antara masyarakat dan perusahaan. Teori legitimasi dapat menjelaskan keterlibatan antara perusahaan dengan pengungkapan sosial dan lingkungan yang menjelaskan bagaimana perusahaan melakukannya serta menjelaskan efek yang didapatkan oleh masyarakat atau publik dari pengungkapan lingkungan (Mousa \& Hassan, 2015).

\section{Teori Pemangku Kepentingan}

Teori pemangku kepentingan berpendapat bahwa perusahaan harus menjadikan pengungkapan sosial sebagai tanggung jawab kepada pemangku kepentingan (Freeman \& Velamnuri, 2006). Teori pemangku kepentingan mengusulkan bahwa keberhasilan perusahaan tergantung pada keberhasilan pengelolaan hubungannya dengan para pemangku kepentingan (Elijido-ten, 2004).

\section{Pengungkapan Akuntansi Lingkungan}

Tidak ada definisi pengungkapan lingkungan yang didefinisikan atau diterima secara universal (Baalouch et al., 2019). Menurut Ikhsan (2008), dari sudut pandang fungsi eskternal akuntansi lingkungan, pengungkapan akuntansi lingkungan dapat dikatakan sebagai suatu jenis pengungkapan sukarela. Oleh karena itu, data akuntansi lingkungan eksternal perlu diungkapkan untuk memperjelas data yang telah diungkapkan sehingga pemangku kepentingan dapat memperoleh pemahaman yang konsisten tentang data akuntansi lingkungan (Nisa, 2017).

\section{Pengaruh Pengungkapan Akuntansi Lingkungan dan Ukuran Perusahaan}

Pada perusahaan besar, risiko politik yang dihadapi biasanya lebih besar jika dibandingkan dengan perusahaan kecil sehingga membuat perusahaan bersar melakukan pengungkapan lebih daripada perusahaan kecil (Riantani \& Nurzamzam, 2015). Blessed et al. (2019) menyatakan dalam risetnya bahwa, entitas besar cenderung melakukan pengungkapan lebih akan informasi lingkungan daripada perusahaan kecil. Perusahaan besar berada di bawah pengawasan regulator, analis, dan pemangku kepentingan lainnya sehingga lebih banyak melakukan pengungkapan. Hasil riset ini searah dengan riset-riset yang telah dikaji oleh T. M. H. Nguyen et al. (2020), Soa et al. (2018), Liu dan Anbumozhi (2017), Ijma et al. (2018), Omoye dan Oshilim (2018) dan State (2012).

$\mathrm{H}_{1}$ : Ukuran perusahaan berpengaruh signifikan positif terhadap pengungkapan akuntansi lingkungan.

\section{Pengaruh Pengungkapan Akuntansi Lingkungan dan Profitabilitas}

Menurut Blessed et al. (2019) profitabilitas perusahaan yang tinggi akan membuat perusahaan lebih melakukan pengungkapan akuntansi lingkungan di mana perusahaan dengan kinerja keuangan yang baik akan lebih melakukan pengungkapan informasi lingkungan karena bagi perusahaan biaya yang dikeluarkan untuk mengungkapkan informasi tidak signifikan jika dibanding dengan jumlah pendapatan perusahaan. Saraswati et al. (2021) juga menyatakan bahwa dengan profitabilitas yang besar maka akan memotivasi manajer untuk memberi informasi secara terperinci termasuk kebebasan dan keleluasaan perusahaan untuk menjelaskan semua rencana sosial mereka. Dengan ini manajer ingin meyakinkan investor tentang profitabilitas perusahaan. $\mathrm{H}_{2}$ : Profitabilitas berpengaruh signifikan positif terhadap pengungkapan akuntansi lingkungan.

\section{Pengaruh Pengungkapan Akuntansi Lingkungan dan Leverage}


Pemberi pinjaman serta investor dalam suatu entitas bergantung pada laporan keuangan dan tingkat kredit perusahaan untuk evaluasi posisi keuangan. Dengan demikian, manajer cenderung meningkatkan pengungkapan lingkungan (Blessed et al., 2019). Menurut Liu et al. (2019) serta Chiu et al. (2020) adanya kecenderungan di mana leverage yang tinggi pada perusahaan akan meningkatkan pengungkapan akuntansi lingkungan di mana dapat mempererat hubungan dengan kreditur ataupun investor karena dapat meyakinkan bahwa perusahaan mampu membayar kewajibannya.

$\mathrm{H}_{3}$ : Leverage berpengaruh signifikan positif terhadap pengungkapan akuntansi lingkungan.

\section{Pengaruh Pengungkapan Akuntansi Lingkungan dan Periode Listing}

Berdasar riset dari T. M. H. Nguyen et al. (2020) perusahaan dengan waktu terdaftar yang lama memiliki keunggulan lebih dalam meningkatkan kondisi untuk mendukung keterbukaan informasi, meningkatkan teknologi dan memenuhi biaya untuk pengungkapan informasi lingkungan. Hasil yang sama juga didukung oleh penelitian Soa et al. (2018), L. S. Nguyen et al. (2017), Welbeck et al. (2017) dan Elshabasy (2018).

$\mathrm{H}_{4}$ : Periode listing berpengaruh signifikan positif terhadap pengungkapan akuntansi lingkungan.

\section{Pengaruh Pengungkapan Akuntansi Lingkungan dan Auditor Independen}

Dengan sifat pengungkapan informasi lingkungan yang bersifat sukarela maka auditor berperan untuk memastikan bahwa informasi yang diungkapkan entitas baik dalam hal keuangan ataupun non-keuangan dilakukan secara adil dan mewakili apa yang dimaksudkan (Welbeck et al., 2017). T. M. H. Nguyen et al. (2020) dalam penelitiannya menyatakan bahwa dengan menggunakan perusahaan audit independen maka laporan yang diungkapkan akan lebih terstruktur dan sesuai standar. Selain itu, juga dapat memuaskan pemangku kepentingan karena laporan informasi lingkungan lebih dapat dipercaya sehingga perusahaan akan melakukan pengungkapan lingkungan yang lebih banyak lagi. Riset yang dilakukan oleh Soa et al. (2018), Suttipun dan Stanton (2012), serta L. S. Nguyen et al. (2017) juga menemukan hubungan positif antara perusahaan audit yang digunakan perusahaan dengan pengungkapan informasi akuntansi lingkungan.

$\mathrm{H}_{5}$ : Auditor independen berpengaruh signifikan positif terhadap pengungkapan akuntansi lingkungan.

\section{Pengaruh Pengungkapan Akuntansi Lingkungan dan Kepemilikan Publik}

Sebuah perusahaan yang mengungkapkan informasi penting dari kegiatan operasionalnya akan meningkatkan ketertarikan publik terhadap perusahaan sehingga akan meningkatkan nilai perusahaan itu sendiri (Japoetra \& Susanto, 2020). Agar masyarakat mau berinvestasi pada perusahaan dan percaya bahwa risiko investasinya rendah, maka perusahaan harus menunjukkan kepada masyarakat keunggulan dan keberadaan perusahaan. Keunggulan tersebut dapat tercapai dengan dilakukannya pengungkapan tanggung jawab sosial perusahaan (CSR) pada laporan keuangannya (Rindiyawati \& Arifin, 2019). Hal yang sama ditemukan pada riset yang dilakukan oleh Rahayu dan Anisyukurlillah (2015) serta Saputra (2019).

$\mathrm{H}_{6}$ : Kepemilikan Publik berpengaruh signifikan positif terhadap pengungkapan akuntansi lingkungan.

\section{Pengaruh Pengungkapan Akuntansi Lingkungan dan Reputasi Perusahaan}

Berdasar pada studi yang dikaji Suryani dan Rofida (2020), perusahaan yang memiliki reputasi baik dan memiliki apresiasi di bidang lingkungan akan lebih banyak mengungkapkan akuntansi lingkungan. Reputasi perusahaan di bidang lingkungan sangat penting bagi pemangku kepentingan dalam menilai praktik perusahaan dalam merawat lingkungan. Perusahaan menanggapinya dengan berusaha mempertahankan reputasi yang baik melalui pengungkapan tersebut (Suryani \& Rofida, 2020). Penelitian ini sesuai dengan riset oleh Syabilla et al. (2021) 
dan Wu dan Shen (2010).

$\mathrm{H}_{7}$ : Reputasi perusahaan berpengaruh signifikan positif terhadap pengungkapan akuntansi lingkungan.

\section{METODE}

Penelitian ini merupakan penelitian kuantitatif yang di mana dilakukan dengan menguji hipotesis untuk mengetahui pengaruh yang ditimbulkan dari variabel dependen serta independen. Riset menggunakan perseroan yang tercatat di Bursa Efek Indonesia (BEI) dari 2016-2020 untuk menjadi objek penelitian. Metode purposive sampling digunakan dalam pemungutan data sampel sehingga sampel dalam penelitian ini terbatas pada objek tertentu sesuai dengan ketentuan yang dibuat (Bungin, 2017). Kriteria perusahaan yang dijadikan sebagai sampel penelitian, yaitu: (1) terdaftar di BEI selama 5 tahun pada periode 2016-2020; (2) menerbitkan laporan keberlanjutan secara lengkap periode 2016-2020; (3) menerbitkan laporan keuangan secara lengkap periode 2016-2020.

\section{Variabel Dependen}

Pengungkapan akuntansi lingkungan merupakan variabel dependen pada penelitian ini. Pengungkapan akuntansi lingkungan merujuk pada indikator Global Reporting Initiative G4. Dalam GRI terdapat 12 bidang untuk kategori lingkungan yang di dalamnya terdapat 34 indikator. Berikut kriteria penilaian kualitas pengungkapan lingkungan:

Tabel 1. Pengukuran Variabel Dependen

\begin{tabular}{cl}
\hline Skor & \multicolumn{1}{c}{ Kriteria } \\
\hline 0 & Tidak ada pengungkapan secara kuantitatif maupun kualititatif \\
1 & $\begin{array}{l}\text { Pengungkapan informasi kuantitatif pada nilainya tanpa pengungkapan objek dan informasi } \\
\text { kualitatif }\end{array}$ \\
2 & $\begin{array}{l}\text { Pengungkapan informasi kuantitatif pada nilai dan objek tanpa pengungkapan informasi } \\
\text { kualitatif }\end{array}$ \\
3 & Melakukan pengungkapan secara kualitatif tanpa pengungkapan kuantitatif \\
4 & Melakukan pengungkapan secara kuantitatif dan kualitatif \\
\hline
\end{tabular}

Sumber: Data Penelitian, 2021

Kemudian dihitung dengan rumus:

$\mathrm{Y}=\sum_{i=1}^{34} \frac{X i}{34}$

Y: Indeks pengungkapan akuntansi lingkungan

Xi: Nilai dari informasi item i yang diungkapkan

\section{Variabel Independen}

Terdapat 7 variabel independen yang diuji dalam penelitian ini. Ukuran perusahaan ialah ukuran badan usaha yang dinilai dari jumlah aset serta segala sumber dayanya (Sastrawan \& Latrini, 2016).

\section{Ukuran Perusahaan $=$ Log $($ Total Aset $)$}

Profitabilitas didapatkan perusahaan setelah perusahaan beroperasi selama periode tertentu. Profitabilitas ialah potensi suatu entitas dalam memanfaatkan dana aset yang dimiliki oleh entitas di mana memperhitungkan kemampuan entitas dalam menghasilkan keuntungan dari kegiatan operasional usahanya pada periode tertentu (Dewi \& Wirajaya, 2013).

$$
\text { Profitabilitas }=\frac{\text { Net Profit }}{\text { Total Ekuitas }}
$$

Leverage diartikan sebagai suatu pengukuran yang mengukur kebergantungan suatu entitas akan kreditur terhadap pembiayaan aset perusahaan (Karina, 2013). Peusahaan yang memiliki sumber dana pinjaman akan mengharapkan keutungan yang didapatkan dari peminjaman tersebut.

$$
\text { Leverage }=\frac{\text { Total Liabilitas }}{\text { Total Aset }}
$$

Periode Listing merupakan waktu perusahaan tercatat dalam bursa efek Indonesia atau BEI. Periode Listing dihitung dengan mengurangi tahun berjalan dengan tahun perusahaan terdaftar di 
BEI.

Auditor memiliki peran dalam mendukung isi laporan tahunan entitas. Auditor juga bertanggung jawab untuk memastikan bahwa informasi yang diungkapkan entitas baik dalam hal keuangan ataupun non-keuangan dilakukan secara adil dan mewakili apa yang dimaksudkan (Welbeck et al., 2017). Pengukuran dilakukan dengan variabel dummy, satu (1) jika laporan keuangan suatu entitas diaudit oleh Big 4 dan nol (0) jika diaudit oleh perusahaan audit lainnya.

Kepemilikan perusahaan oleh publik diwakili oleh kepemilikan saham publik. Kepemilikan publik dapat diartikan sebagai suatu proporsi saham yang telah dimiliki oleh masyarakat (Suhartono et al., 2018). Kepemilikan publik dalam suatu perusahaan menunjukkan adanya informasi pribadi yang harus dibagikan oleh perusahaan kepada publik (Rahmawati \& Hutami, 2019).

$$
\text { Kepemilikan Publik }=\frac{\text { Jumlah Saham Publik }}{\text { Jumlah Saham Beredar }}
$$

Reputasi adalah cara pandang pihak lain terhadap suatu perusahaan, seseorang, suatu komite, atau suatu kegiatan. Reputasi perusahaan digunakan oleh pemangku kepentingan untuk mengukur nilai suatu organisasi (Gara, 2020). Pengukuran dilakukan dengan variabel dummy, satu (1) jika perusahaan pernah mendapatkan penghargaan dalam bidang lingkungan dan nol (0) jika perusahaan tidak pernah mendapatkan penghargaan dalam bidang lingkungan.

Pada riset ini digunakan metode analisis regresi panel untuk melakukan pengujian hubungan variabel independen terhadap variabel dependennya. Proses pengujian data menggunakan aplikasi SPSS untuk melakukan pengujian statistik deskriptif serta pengujian outlier. Dalam melakukan uji F, uji t dan uji determinasi digunakan aplikasi Eviews. Pendeteksian data outlier dilakukan dengan menggunakan Studentized Deleted Residual (SDR) di mana batasannya adalah antara 1,96 hingga 1,96. Dalam melakukan regresi panel ada tiga metode yang dapat digunakan. Metode tersebut, yaitu Pooled Least Square (PLS), Fixed Effect Model (FEM) dan Random Effect Model (REM). Uji chow dan uji hausman diterapkan dalam riset ini guna untuk memilih model yang paling tepat.

Persamaan regresi penelitian ini, yaitu:

ENVI $=\alpha+\beta_{1} S Z+\beta_{2} P F+\beta_{3} L V+\beta_{4} L P+\beta_{5} I N+\beta_{6} K P+\beta_{7} R P+\varepsilon$

Keterangan:

ENVI = Pengungkapan Akuntansi Lingkungan

$\alpha \quad=$ Konstan

$\beta_{1-7}=$ Koefisien Regresi

SZ = Ukuran Perusahaaan

$\mathrm{PF} \quad=$ Profitabilitas

$\mathrm{LV}=$ Leverage

LP = Periode Listing

IN = Independensi Auditor

$\mathrm{KP} \quad=$ Kepemilikan Publik

RP = Reputasi Perusahaan

$\varepsilon \quad=$ Error

\section{Sampel Penelitian}

HASIL

Berdasarkan kriteria perusahaan yang dijadikan sebagai sampel penelitian, berikut merupakan hasil pemilahan sampel dalam penelitian ini.

Tabel 2. Sampel Penelitian

\begin{tabular}{lc}
\hline \multicolumn{1}{c}{ Keterangan } & Jumlah \\
\hline Perusahaan yang tercantum di BEI per 31 Des 2020 & 713 \\
Perusahaan yang tidak terdaftar di BEI selama 5 tahun pada periode 2016-2020 & $(200)$ \\
Perusahaan yang tidak menerbitkan laporan keberlanjutan secara lengkap periode 2016-2020 & $(469)$ \\
Perusahaan yang tidak menerbitkan laporan keuangan secara lengkap periode 2016-2020 & $(0)$
\end{tabular}


Owner: Riset \& Jurnal Akuntansi

e-ISSN : 2548-9224 | p-ISSN : 2548-7507

Volume 6 Nomor 1, Januari 2022

DOI : https://doi.org/10.33395/owner.v6i1.542

Total perusahaan sampel

\begin{tabular}{c}
\hline 44 \\
5 \\
\hline 220 \\
$(37)$ \\
\hline 183
\end{tabular}

Tahun penelitian

Total data

Data outlier

Jumlah sampel penelitian

Sumber: Data yang diolah, 2021

Pada penelitian ini digunakan 44 entitas dari 713 entitas yang terdaftar di BEI untuk dijadikan sebagai sampel penelitian dengan jumlah data uji sebanyak 220 data. Dari data tersebut sebanyak 37 data merupakan data outlier sehingga total data yang dapat dijadikan sebagai sampel penelitian ini adalah sebesar 183 data.

\section{Analisis Statistik Deskriptif}

Tabel statistik deskriptif memberikan informasi mengenai nilai minimun, maksimum, rata-rata dan standar deviasi dari variabel uji. Berikut hasilnya:

Tabel 3. Hasil Uji Statistik Deskriptif

\begin{tabular}{lccccc}
\hline \multicolumn{1}{c}{ Variabel } & $\mathrm{N}$ & Min & Max & Mean & $\begin{array}{c}\text { Std. } \\
\text { Deviation }\end{array}$ \\
\hline $\begin{array}{l}\text { Pengungkapan } \\
\text { Akuntansi Lingkungan }\end{array}$ & 220 & 0 & 2,73529 & 0,84947 & 0,60288 \\
$\begin{array}{l}\text { Ukuran Perusahaan } \\
\text { (dalam jutaan) }\end{array}$ & 220 & 2.106 .963 & 1.511 .804 .628 & 177.537 .206 & 337.993 .669 \\
Profitabilitas & 220 & $-4,11253$ & 1,45088 & 0,10477 & 0,42654 \\
Leverage & 220 & 0,12642 & 1,91608 & 0,60600 & 0,23767 \\
Periode Listing & 220 & 0 & 43 & 19,27273 & 10,02591 \\
Kepemilikan Publik & 220 & 0,01290 & 0,77328 & 0,29848 & 0,15374 \\
\hline
\end{tabular}

Sumber: Data yang diolah, 2021

Pengungkapan lingkungan maksimum senilai 2,73529 dimiliki Perusahaan Gas Negara (Persero) Tbk tahun 2020 dan nilai minimum sebesar 0 dimiliki berbagai perusahaaan secara bersamaaan. Rata-rata nilai pengungkapan sebesar 0,84947 dan nilai standar deviasi adalah 0,60288. Ukuran perusahaan terbesar senilai 1.511.804.628 dimiliki Bank Rakyat Indonesia (Persero) tahun 2020, ukuran terkecil senilai 2.106.963 dimiliki PT Lotte Chemical Titan Tbk tahun 2020 dengan nilai standar deviasi 337.993.669. Profitabilitas minimum senilai $-4,11253$ dimiliki PT Waskita Beton Precast Tbk tahun 2020 dan profitabilitas terbesar senilai 1,45088 dimiliki PT Unilever Indonesia Tbk tahun 2020 dengan nilai standar deviasi 0,42654 dan nilai rata-rata sebesar 0,42654 .

Leverage memiliki nilai minimum sebesar 0,12642 dimiliki PT Vale Indonesia Tbk tahun 2019, nilai maksimum sebesar 1,91608 dimiliki PT Bumi Resources Tbk tahun 2016, nilai ratarata sebesar 0,60600 dan standar deviasi sebesar 0,23767. Perusahaan BEI rata-rata telah mendaftarkan perusahaannya pada BEI selama 19 tahun. Entitas yang terdaftar paling lama di BEI adalah PT Solusi Bangun Indonesia Tbk dan perusahaan yang paling baru mendaftarkan entitasnya di BEI adalah PT Waskita Beton Precast Tbk. Kepemilikan publik maksimum sebesar 0,77328 dimiliki PT Bumi Resources Tbk tahun 2019, nilai minimum sebesar 0,01290 dimiliki Bank Permata Tbk tahun 2020 dengan nilai rata-rata sebesar 0,29848 serta standar deviasi sebesar 0,15374 .

Variabel dummy disajikan dalam hasil uji frekuensi. Berikut hasil uji frekuensi:

Tabel 4. Hasil Uji Frekuensi

\begin{tabular}{llll}
\hline Variabel & Kategori & Frekuensi & Persen \\
\hline \multirow{2}{*}{ Big 4} & $0=$ non-Big 4 & 53 & $24,09 \%$ \\
& $1=$ Big 4 & 167 & $75,91 \%$ \\
\hline \multirow{2}{*}{ Reputasi } & $0=$ Tidak mendapat penghargaan lingkungan & 105 & $47,73 \%$
\end{tabular}


$\begin{array}{llll}\text { Perusahaan } & 1=\text { Mendapat penghargaan lingkungan } & 115 & 52,27 \%\end{array}$

\section{Sumber: Data yang diolah, 2021}

Dari data yang didapatkan, rata-rata perusahaan yang tercatat di BEI mengaudit laporannya pada kantor akuntan publik (KAP) Big $4(75,91 \%)$. Selain, itu, sebagian besar perusahaan pernah mendapatkan penghargaan di bidang lingkungan $(52,27 \%)$.

\section{Hasil Uji Chow}

Dalam pengujian chow akan membandingkan antara PLS dan FEM sebagai model yang paling tepat untuk melakukan penelitian. Berikut hasil pengujiannya:

Tabel 5. Hasil Uji Chow

\begin{tabular}{ccc}
\hline Effect Test & Prob. & Kesimpulan \\
\hline Cross-section Chi-square & 0,00000 & Fixed Effect Model \\
\hline Sumber: Data yang diolah, 2021 &
\end{tabular}

Dari data ini memperlihatkan bahwa hasil uji chow adalah sebesar 0,0000. Hal ini menunjukkan bahwa model paling cocok adalah FEM.

\section{Hasil Uji Hausman}

Dalam pengujian hausman dilakukan penentuan antara REM dan FEM sebagai model yang paling tepat untuk melakukan penelitian. Berikut hasil pengujiannya:

Tabel 6. Hasil Uji Hausman

\begin{tabular}{ccc}
\hline Effect Test & Prob. & Kesimpulan \\
\hline Cross-section Random & 0,00000 & Fixed Effect Model \\
\hline
\end{tabular}

Sumber: Data yang diolah, 2021

Data memperlihatkan bahwa hasil uji hausman adalah sebesar 0,00000. Hal ini menunjukkan bahwa model paling cocok adalah FEM.

\section{Hasil Uji F}

Uji $\mathrm{F}$ digunakan untuk melakukan pengujian pengaruh hubungan variabel dependen pada independennya secara simultan.

Tabel 7. Hasil Uji F

\begin{tabular}{ccc}
\hline Effect Test & Prob. & Kesimpulan \\
\hline Prob(F-statistic) & 0,00000 & Signifikan \\
\hline \multicolumn{2}{c}{ Sumber: Data yang diolah, 2021 } &
\end{tabular}

Berdasar hasil uji $\mathrm{F}$, menunjukkan angka signifikansi senilai 0,00000 maka variabel leverage, profitabilitas, ukuran perusahaan, periode listing, kepemilikan publik dan reputasi perusahaan secara simultan mempengaruhi pengungkapan akuntansi lingkungan.

\section{Hasil Uji t}

Uji t dilakukan untuk menguji apakah hipotesis penelitian dapat diterima/tidak. Berikut hasil uji t:

Tabel 8. Hasil Uji t

\begin{tabular}{llrll}
\hline Variable & Koefisien & Prob. & Kesimpulan & Hipotesis \\
\hline Constant & 6,289208 & 0,1752 & & \\
SZ & $-0,237033$ & 0,1291 & Tidak Signifikan & Tidak Terbukti \\
PF & $-0,360075$ & 0,0000 & Signifikan Negatif & Tidak Terbukti \\
LV & 0,590669 & 0,0070 & Signifikan Positif & Terbukti \\
LP & 0,067304 & 0,0001 & Signifikan Positif & Terbukti \\
IN & 0,188123 & 0,0967 & Tidak Signifikan & Tidak Terbukti \\
KP & 0,362467 & 0,6833 & Tidak Signifikan & Tidak Terbukti \\
RP & 0,209097 & 0,0229 & Signifikan Positif & Terbukti \\
\hline
\end{tabular}

Sumber: Data yang diolah, 2021

Berdasarkan hasil uji, didapatkan persamaan regresi yaitu: 


\section{$\mathrm{ENVI}=$ 6,289208 - 0,237033 SZ - 0,360075 PF + 0,590669 LV + 0,067304 LP + 0,188123 IN + $0,362467 \mathrm{KP}+0,209097 \mathrm{RP}+\varepsilon$}

Ukuran perusahaan memiliki nilai signifikansi lebih besar dari (>) 0,05 yaitu 0,1291 sehingga ditemukan bahwa ukuran perusahaan tidak memberikan pengaruh pada pengungkapan akuntansi lingkungan, maka hipotesis 1 ditolak. Profitabilitas memiliki signifikan lebih kecil dari $(<) 0,05$ di mana nilainya adalah 0,0000 disertai dengan koefisien yang negatif yang menunjukkan bahwa profitabilitas mempengaruhi pengungkapan akuntansi lingkungan secara negatif, sehingga hipotesis 2 ditolak. Nilai signifikansi leverage adalah 0,0070 disertai dengan nilai koefisien positif yang mengindikasikan bahwa leverage mempengaruhi pengungkapan akuntansi lingkungan secara positif, sehingga hipotesis 3 dapat diterima. Periode listing memiliki koefisien 0,067304 dengan nilai signifikansi $<0,05$ yaitu 0,0001 yang menunjukkan bahwa periode listing mempengaruhi pengungkapan akuntansi lingkungan secara signifikan positif, maka hipotesis 4 diterima.

Nilai signifikansi variabel independensi auditor adalah 0,0967 dengan nilai koefisien sebesar 0,188123, sehingga didapatkan hasil bahwa independensi auditor tidak memberikan pengaruh signifikan terhadap pengungkapan akuntansi lingkungan, sehingga hipotesis 5 ditolak. Kepemilikan publik memiliki signifikan $>0,05$ di mana nilai koefisiennya adalah 0,6833, hal ini menunjukkan bahwa kepemilikan publik tidak mempengaruhi pengungkapan lingkungan, sehingga hipotesis 6 ditolak. Reputasi perusahaan memiliki nilai koefisien 0,209097 dengan nilai signifikansi < 0,05 yaitu 0,0229 yang menunjukkan bahwa reputasi perusahaan mempengaruhi pengungkapan akuntansi lingkungan secara signifikan positif. Dengan hasil ini, maka hipotesis 7 diterima.

\section{Hasil Uji Koefisien Determinasi}

Uji koefisien determinasi dimanfaatkan agar bisa mengetahui presentase penjelasan variabel independen terhadap variabel dependennya. Berikut hasil uji koefisien determinasi:

\begin{tabular}{cc} 
Tabel 9. Hasil Uji Koefisien Determinasi \\
\hline Variabel Dependen & Adjusted $\mathbf{R}^{2}$ \\
\hline Pengungkapan Akuntansi Lingkungan & 0,82246 \\
\hline
\end{tabular}

Sumber: Data yang diolah, 2021

Hasil adjusted $\mathrm{R}^{2}$ adalah sebesar 0,82246 atau $82,2 \%$. Dari hasil ini dapat diketahui bahwa variabel independen (ukuran perusahaan, profitabilitas, leverage, periode listing, indepedensi auditor, kepemilikan publik dan reputasi perusahaan) mampu menjelaskan variabel dependen (pengungkapan akuntansi lingkungan) sebesar 82,2\% dan sisanya yaitu sebesar 17,8\% dijelaskan oleh variabel lain yang tidak ada dalam penelitian.

\section{PEMBAHASAN}

\section{Pengaruh Pengungkapan Akuntansi Lingkungan dan Ukuran Perusahaan}

Hasil didukung dengan riset yang dilakukan oleh Elshabasy (2018) dan Kiswanto (2020) yang di mana menyimpulkan bahwa tidak ada hubungan antara ukuran perusahaan dan pengungkapan yang dilakukan oleh perusahaan. Tingkat pengungkapan lingkungan lebih berdasarkan kepada aktivitas dan objektifitas perusahaan untuk mencapai laba, perusahaan besar tidak selalu menerapkan CSR karena beranggapan bahwa pemegang saham tidak akan memperhatikan hal tersebut dan lebih memperhatikan laba operasi perusahaan. Menurut Kiswanto (2020), bagi perusahaan besar masyarakat umum kebanyakan tidak begitu memperhatikan dampak yang terjadi terhadap lingkungan sebagai hasil dari kegiatan operasional perusahaan, pengungkapan yang diungkapkan oleh perusahaan besar kebanyakan didasari pada tujuan serta kegiatan-kegiatan yang ada di dalam perusahaan dengan tujuan agar perusahaan memiliki laba yang semakin besar.

\section{Pengaruh Pengungkapan Akuntansi Lingkungan dan Profitabilitas}

Riset yang dilakukan Diantimala dan Amril (2018) dan Ompusunggu (2016) juga menunjukkan 
hubungan negatif antara pengungkapan lingkungan dan profitabilitas. Perusahaan dengan profitabilitas yang lebih besar biasanya akan memiliki tingkat kepatuhan yang tinggi terhadap peraturan lingkungan daripada perusahaan dengan profitabilitas yang lebih kecil, hal ini membuat perusahaan cenderung memiliki lebih sedikit masalah lingkungan untuk diungkapkan sehingga membuat perusahaan untuk tidak mengungkapkan dampak kegiatan mereka terhadap lingkungan (Diantimala \& Amril, 2018). Perusahaan juga akan melakukan pengungkapan lingkungan lebih jika profitabilitas perusahaan rendah karena investor dan juga publik akan memandang perusahaan dengan lebih baik dan terus melakukan investasi walaupun perusahaan memiliki profitabilitas yang rendah. Hasil bertentangan dengan teori pemangku kepentingan yang menyatakan perusahaan dengan profitabilitas tinggi akan lebih ambisius dan melakukan pengungkapan.

\section{Pengaruh Pengungkapan Akuntansi Lingkungan dan Leverage}

Riset yang dilakukan oleh Blessed et al. (2019), Chiu et al. (2020) dan Fatima et al. (2015) juga menyatakan bahwa leverage memiliki hubungan signifikan positif dengan pengungkapan akuntansi lingkungan. Perusahaan akan lebih beresiko karena ketergantungannya kepada utang, sehingga perusahaan akan lebih menungkapkan tanggung jawab mereka akan lingkungan agar masyarakat dapat percaya bahwa dampak operasional dari kegiatan usaha perusahaan kecil terhadap lingkungan, sehingga menunjukkan tanggung jawab perusahaan juga (Fatima et al., 2015). Hal ini juga bisa terjadi karena perusahaan perlu meyakinkan para investor dan juga kreditur bahwa perusahaan dapat membayar kewajiban perusahaan secara penuh dengan hal ini dapat mempererat hubungan yang terjalin dengan perusahaan juga.

\section{Pengaruh Pengungkapan Akuntansi Lingkungan dan Periode Listing}

Hasil menunjukkan bahwa tidak ada hubungan antara pengungkapan akuntansi lingkungan dengan periode listing. Hasil didukung dengan riset yang dilakukan oleh T. M. H. Nguyen et al. (2020), Soa et al. (2018), Welbeck et al. (2017), dan Elshabasy (2018). Perusahaan dari waktu ke waktu akan mengembangkan praktik usahanya menjadi lebih baik, sehingga perusahaan yang tercatat lebih lama akan memperdulikan pandangan masyarakat terhadap perusahaan sehingga perusahaan akan melakukan pengungkapan lingkungan agar memposisikan mereka sebagai entitas yang memiliki tanggung jawab tinggi secara sosial maupun lingkungan (Welbeck et al., 2017). Selain itu, perusahaan dengan waktu terdaftar yang lama memiliki keunggulan baik dari segi teknologi, biaya maupun wawasan karena pengalaman yang dimilikinya. Menurut Soa et al., (2018), semakin lama perusahaan terdaftar di pasar saham maka akan memudahkan mereka untuk mematuhi persyaratan pengungkapan juga.

\section{Pengaruh Pengungkapan Akuntansi Lingkungan dan Auditor Independen}

Hasil sejalan dengan riset yang dikemukakan oleh Odoemelam dan Okafor (2018) dan Welbeck (2017) yang dalam hasil risetnya menunjukan bahwa perusahaan audit tidak memberi pengaruh kepada pengungkapan lingkungan perusahaan. Dari hasil penelitian baik perusahaan yang menggunakan perusahaan Big 4 maupun perusahaan non-Big 4 tidak akan mempengaruhi pengungkapan informasi lingkungan, walaupun dengan adanya keterlibatan antara perusahaan dan Big 4 diharapkan dapat memberikan suatu pengaruh positif terhadap perusahaan, namun hal ini tidak memberikan pengaruh pada pengungkapan perusahaan terutama pada pengungkapan akuntansi lingkungan.

\section{Pengaruh Pengungkapan Akuntansi Lingkungan dan Kepemilikan Publik}

Hasil uji selaras dengan pengujian yang dilakukan Johan (2021) di mana tidak ditemukan adanya hubungan antara kepemilikan publik kepada pengungkapan lingkungan. Dari hasil dapat dikatakan bahwa masyarakat sebagai investor suatu perusahaan dalam menanamkan modalnya kurang memperhatikan aspek keterbukaan informasi lingkungan perusahaan yang di mana 
merupakan bentuk tanggung jawab perusahaan untuk meminimalisir kerusakan lingkungan dalam proses bisnisnya. Hasil yang sama juga dinyatakan pada penelitian oleh Rahmawati dan Hutami (2019).

\section{Pengaruh Pengungkapan Akuntansi Lingkungan dan Reputasi Lingkungan}

Hasil searah dengan riset yang dikaji oleh Syabilla et al. (2021), Suryani dan Rofida (2020) dan Dewi (2019) yang menunjukkan hubungan positif antara reputasi lingkungan dan pengungkapan lingkungan. Perusahaan yang memiliki reputasi baik akan lebih melakukan apresiasi terhadap lingkungan sekitar terutama yang mendapatkan dampak dari aktivitas perusahaan dan melakukan lebih banyak pengungkapan akuntansi lingkungan (Syabilla et al., 2021). Perusahaan dengan reputasi baik akan melakukan pengungkapan agar dapat meningkatkan hubungan baik antara perusahaan dengan pemangku kepentingan yang di mana akan menjamin keberlangsungan perusahaan dalam jangka panjang. Dengan melakukan pengungkapan lingkungan juga dapat menghindari perusahaan dari resiko reputasi perusahaan (Rosiyana, 2019).

\section{KESIMPULAN}

Berdasar pada hasil riset dalam pengujian hubungan antara variabel independen terhadap variabel dependen dapat ditemukan jawaban dari hipotesis penelitian. Pada penelitian ditemukan bahwa ukuran perusahaan, independensi auditor serta kepemilikan publik tidak memberikan pengaruh terhadap pengungkapan akuntansi lingkungan.

Reputasi perusahaan berpengaruh secara positif terhadap pengungkapan akuntansi lingkungan. Reputasi perusahaan diukur dengan banyaknya penghargaan lingkungan yang diterima perusahaan, maka dengan banyaknya penghargaan tersebut akan meningkatkan pengungkapan lingkungan. Temuan ini dapat menjadi acuan bagi pemerintah untuk lebih mempromosikan program-program terkait penghargaan di bidang lingkungan sehingga semakin banyak perusahaan yang termotivasi untuk berpartisipasi dalam program tersebut dan dapat meningkatkan pengungkapan lingkungan.

Leverage memberikan pengaruh positif terhadap pengungkapan akuntansi lingkungan. Dapat dikatakan kebergantungan pada kreditur akan meningkatkan pengungkapan lingkungan. Kreditur akan memperhatikan dampak usaha akan lingkungan di mana mereka melakukan pembiayaan. Jika kerusakan lingkungan terjadi atas akibat dari operasi perusahaan maka dapat mempengaruhi keberlanjutan perusahaan yang di mana dapat mengganggu kemampuan perusahaan dalam pelunasan hutang. Oleh karena itu, perusahaan dengan pembiayaan hutang yang tinggi harus berhati-hati dengan memperbanyak kegiatan dan pengungkapan lingkungan agar tidak memperkecil kesempatan peminjaman dana oleh kreditur.

Periode listing berpengaruh secara positif terhadap pengungkapan akuntansi lingkungan. Dengan kata lain, semakin lama waktu listing suatu perusahaan akan meningkatkan pengungkapan karena perusahaan akan memiliki keunggulan dari pengalamannya baik dalam keterbukaan informasi maupun pemahamannya akan pengungkapan. Dari hal ini, perusahaan yang belum atau baru saja terdaftar di bursa efek akan memiliki wawasan yang lebih sedikit dibandingkan dengan perusahaan yang sudah terdaftar lama. Sehingga, perusahaan perlu menambah wawasan dengan mempelajari cara perusahaan yang sudah lama terdaftar pada bursa efek dalam melaksanakan pengungkapannya dan meningkatkan pengungkapan lingkungan oleh perusahaan itu sendiri.

Profitabilitas mempengaruhi pengungkapan akuntansi lingkungan secara negatif. Perusahaan dengan profitabilitas baik tidak banyak melakukan pengungkapan. Perusahaan dengan profit tinggi harusnya memiliki kebebasan biaya dalam hal pengungkapan namun tidak dilakukan yang di mana bisa terjadi karena kurangnya regulasi yang ketat ataupun karena sifat pelaporan yang sukarela. Oleh karena itu, peran pemerintah dalam hal ini menjadi sangat penting, pemerintah dapat lebih memperketat regulasi yang berkaitan dengan pengungkapan lingkungan sehingga dapat meningkatkan pengungkapan informasi lingkungan oleh perusahaan juga. 
Adapun keterbatasan dalam penelitian di mana jumlah sampel yang diambil terbatas pada 5 tahun yaitu dari tahun 2016-2020, selain itu adanya limitasi dalam data uji karena masih banyak perusahaan yang tidak menerbitkan laporan keberlanjutan selama 5 periode. Pengembangan untuk penelitian selanjutnya dapat dilakukan dengan menambah variabel-variabel yang tidak ada di dalam penelitian ini seperti kepemilikan keluarga, jenis industri dan lainnya serta memperluas ruang lingkup penelitian dengan melakukan penelitian pada perusahaan selain di BEI.

\section{REFERENSI}

Amidjaya, P. G., \& Widagdo, A. K. (2020). Sustainability reporting in Indonesian listed banks: Do corporate governance, ownership structure and digital banking matter? Journal of Applied Accounting Research, 21(2), 231-247. https://doi.org/10.1108/JAAR-09-2018-0149

Amosh, H. A. M. Al, \& Mansor, N. (2018). Sustainability and corporate reporting: A review on environmental and social accounting disclosure. International Journal of Accounting, Finance and Business, 3(8), 78-87. www.ijafb.com

Angela, P., \& Handoyo, S. (2021). The determinants of environmental disclosure quality: empirical evidence from Indonesia. Journal of Accounting Auditing and Business, 4(1), 41. https://doi.org/10.24198/jaab.v4i1.31489

Anugerah, Saraswati, \& Andayani. (2018). Quality of disclosure and corporate social responsibility reporting practices in Indonesia. Jurnal Akuntansi, 22(3), 337. https://doi.org/10.24912/ja.v22i3.392

Aryanti, F., \& Aryani, Y. A. (2020). Kepemilikan publik, tipe industri dan pengungkapan lingkungan: studi komparatif Indonesia dan Singapura. Wahana: Jurnal Ekonomi, Manajemen Dan Akuntansi, 23(2), 131-144. https://doi.org/10.35591/wahana.v23i2.241

Baalouch, F., Ayadi, S. D., \& Hussainey, K. (2019). A study of the determinants of environmental disclosure quality: Evidence from French listed companies. In Journal of Management and Governance (Vol. 23, Issue 4). Springer US. https://doi.org/10.1007/s10997-019-09474-0

Bae, S. M., Masud, M. A. K., \& Kim, J. D. (2018). A cross-country investigation of corporate governance and corporate sustainability disclosure: A signaling theory perspective. Sustainability (Switzerland), 10(8). https://doi.org/10.3390/su10082611

Bidari, G., \& Djajadikerta, H. G. (2020). Factors influencing corporate social responsibility disclosures in Nepalese banks. Asian Journal of Accounting Research, 5(2), 209-224. https://doi.org/10.1108/ajar-03-2020-0013

Blessed, A. D., Fodio, P., \& Inuwa, M. (2019). Effect of corporate attributes on environmental disclosure of listed oil and gas companies in Nigeria. European Journal of Accounting, Auditing and Finance Research, 7(10), 15-16. http://www.ghbook.ir/index.php?name=لهنى ¿ وي ن idoption=com_dbook\&task=readonline\&book_id=13650\&page=73\&chkhashk=ED9C 9491B4\&Itemid=218\&lang=fa\&tmpl=component

Chiu, C. L., Zhang, J., Li, M., Wei, S., Xu, S., \& Chai, X. (2020). A study of environmental disclosures practices in Chinese energy industry. Asian Journal of Sustainability and Social Responsibility, 5(1), 1-21. https://doi.org/10.1186/s41180-020-00036-1

Diantimala, Y., \& Amril, T. A. (2018). The effect of ownership structure, financial and environmental performances on environmental disclosure. Accounting Analysis Journal, 7(1), 70-77. https://doi.org/10.15294/aaj.v7i1.20019 
Ekundayo, G., \& Josiah, M. (2020). Environmental accounting disclosure : A critical examination of literature. British Journal of Economics, Finance and Management Science, 17(2), 3445 .

Elijido-ten, E. (2004). Determinants of environmental disclosures in a developing country: an application of the stakeholder theory. Fourth Asia Pacific Interdisciplinary Research in Accounting Conference, July, 1-28.

Elshabasy, Y. N. (2018). The impact of corporate characteristics on environmental information disclosure: An empirical study on the listed firms in Egypt. Journal of Business and Retail Management Research, 12(2), 232-241. https://doi.org/10.24052/jbrmr/v12is02/tioccoeidaesotlfie

Fatima, A. H. A., Abdullah, N., \& Sulaiman, M. (2015). Environmental disclosure quality: Examining the impact of the stock exchange of Malaysia's listing requirements. Social Responsibility Journal, 11(4), 904-922. https://doi.org/10.1108/SRJ-03-2014-0041

Freeman, R. E., \& Velamnuri, S. R. (2006). A new approach to corporate social responsibility company stakeholder responsibility in kakabadse a, morsine, corporate social responsibility: Reconciling aspiration with application.

Gara, R. (2020). Company profitability and reputation: Evidence of listed pharmaceutical companies. Accountability Journal, 9(1), 8-15.

Ijma, Haris, N., \& Yusnita, N. (2018). Pengaruh ukuran perusahaan, profitabilitas dan porsi kepemilikan publik, terhadap environtmental disclosure (studi pada perusahaan logam dan mineral lainnya yang terdaftar di bursa efek Indonesia). E-Jurnal Katalogis, 6(4), 1-9.

Ismail, A. H., \& Rahman, A. A. (2016). The quality of environmental disclosure in various reporting media of oil and gas companies in developing countries. Corporate Ownership and Control, 14(1Continued1), 203-218. https://doi.org/10.22495/cocv14i1c1p4

Japoetra, D. B., \& Susanto, Y. K. (2020). Pengungkapan tanggung jawab sosial perusahaan manufaktur: studi empiris tata kelola. Media Bisnis, 12(1), 1-8. https://doi.org/10.34208/mb.v12i1.934

Johan, S. (2021). Determinants of corporate social responsibility provision. Journal of Asian Finance, Economics and Business, 8(1), 891-899. https://doi.org/10.13106/jafeb.2021.vol8.no1.891

Juhmani, O. (2014). Determinants of corporate social and environmental disclosure on websites: The case of Bahrain. Universal Journal of Accounting and Finance, 2(4), 77-87. https://doi.org/10.13189/ujaf.2014.020402

Karokaro, A. S. (2021). Konflik lahan dan kerusakan lingkungan terus terjadi dalam operasi PT TPL. Mongabay. https://www.mongabay.co.id/2021/04/07/konflik-lahan-dan-kerusakanlingkungan-terus-terjadi-dalam-operasi-tpl/

Liu, X., \& Anbumozhi, V. (2017). An empirical study on the influencing factors of environmental information disclosure of Chinese mining listed companies. Journal of Cleaner Production, 17(6), 593-600. https://doi.org/10.1016/j.jclepro.2008.10.001

Maulia, D., \& Yanto, H. (2020). Determinants of environmental disclosure in Indonesia. Journal of Environmental Management and Tourism, 11(3), 682-691. https://doi.org/10.14505/jemt.v11.3(43).22

Meutia, I., Yaacob, Z., \& F. Kartasari, S. (2021). Sustainability reporting: An overview of the 
recent development. Accounting and Financial Control, 3(1), 23-39. https://doi.org/10.21511/afc.03(1).2020.03

Michelon, G., Pilonato, S., \& Ricceri, F. (2015). CSR reporting practices and the quality of disclosure: An empirical analysis. Critical Perspectives on Accounting, 33(December 2017), 59-78. https://doi.org/10.1016/j.cpa.2014.10.003

Mousa, G., \& Hassan, N. (2015). Legitimacy theory and environmental practices: Short notes. International Journal of Business and Statistical Analysis, 2(1), 41-53. https://doi.org/10.12785/ijbsa/020104

Nguyen, L. S., Tran, M. D., Hong Nguyen, T. X., \& Le, Q. H. (2017). Factors affecting disclosure levels of environmental accounting information: The case of Vietnam. Accounting and Finance Research, 6(4), 255. https://doi.org/10.5430/afr.v6n4p255

Nguyen, T. M. H., Nguyen, T. K. T., \& Vi Nguyen, T. T. (2020). Factors affecting the implementation of environmental accounting by construction companies listed on the Ho Chi Minh Stock Exchange. Journal of Asian Finance, Economics and Business, 7(8), 269280. https://doi.org/10.13106/JAFEB.2020.VOL7.NO8.269

Nisa, A. K. (2017). Environmental accounting disclosure in ASEAN countries. The Indonesian Accounting Review, 7(1), 15. https://doi.org/10.14414/tiar.v7i1.943

Odoemelam, N., \& Okafor, R. (2018). The influence of corporate governance on environmental disclosure of listed non-financial firms in Nigeria. Indonesian Journal of Sustainability Accounting and Management, 2(1), 25. https://doi.org/10.28992/ijsam.v2i1.47

Omoye, A. S., \& Oshilim, W. (2018). Antecedents of environmental disclosure in Nigeria. Accounting \& Taxation Review, 2(2), 101-116.

Ompusunggu, J. (2016). The effect of profitability to the disclosure of corporate social responsibility (CSR disclosure) on mining companies listed on Indonesian stock exchange (BEI) in the year 2010-2012. IOSR Journal of Business and Management (IOSR-JBM), 18(6), 69-78. https://doi.org/10.9790/487X-1806016978

Palisetti, G. (2020). Is quality of environmental accounting and disclosure practices adequate? International Journal of Advanced Research in Engineering and Technology, 11(11), 1-8. https://doi.org/10.34218/IJARET.11.11.2020.001

Rahayu, P., \& Anisyukurlillah, I. (2015). Pengaruh kepemilikan saham publik, profitabilitas dan media terhadap pengungkapan tanggung jawab sosial. Accounting Analysis Journal, 4(3), 19. https://doi.org/10.15294/aaj.v4i3.8300

Rahmawati, E., \& Hutami, D. J. S. (2019). The influence of structure ownership, board diversity, and corporate governance perception index (CGPI) toward environmental disclosures and environmental performance as moderating variable (empirical study on companies registered in CGPI and PROPER). Advances in Economics, Business and Management Research, 102(Icaf), 45-52. https://doi.org/10.2991/icaf-19.2019.8

Riantani, S., \& Nurzamzam, H. (2015). Analysis of company size, financial leverage, and profitability and its effect to CSR disclosure. Jurnal Dinamika Manajemen, 6(2), 203-213. https://doi.org/10.15294/jdm.v6i2.4308

Rindiyawati, A., \& Arifin, J. (2019). Determinan pengungkapan corporate social responsibility pada industri perbankan. Jurnal Akuntansi Dan Bisnis, 19(1), 1. https://doi.org/10.20961/jab.v19i1.244 
Rosiyana, D. (2019). Building reputation through environmental disclosure. Indonesian Management and Accounting Research, 18(1), 1. https://doi.org/10.25105/imar.v18i1.5375

Saha, A. K., \& Akter, S. (2013). Relationship between environmental reporting in corporate annual reports \& corporate profitability in Bangladesh. Global Conference on Business \& Finance Proceedings, 8(1)(July), 75-86.

Saputra, S. E. (2019). Pertumbuhan perusahaan dan tipe industri pengungkapan terhadap pengungkapan CSR pada perusahaan high profil di bursa efek Indonesia. Journal of Residu, $3(18), 138-149$.

Saraswati, E., Amalia, R. S., \& Herawati, T. (2021). Determinants of carbon emission disclosure in Indonesia manufacturing company. Asian Journal of Economics, Business and Accounting, 21(3), 1-9. https://doi.org/10.9734/ajeba/2021/v21i330356

Sastrawan, I. P., \& Latrini, M. Y. (2016). Pengaruh profitabilitas, solvabilitas, dan ukuran perusahaan terhadap audit report lag pada perusahaan manufaktur. E-Jurnal Akuntansi Universitas Udayana, 17(1), 311-337.

Soa, N. La, Hang, T. T., \& Nga, N. T. (2018). Factors affecting disclosure level of environmental accounting information - the case of vietnamese firms doing business under the model parent company - subsidiary. The 5th IBSM International Conference on Business, Management and Accounting, April, 710-723.

State, O. (2012). Web-based corporate environmental reporting in Nigeria: a study of listed companies. Informatica Economica Journal, 16(3), 27-36.

Suhartono, Mawarni, I., \& Wahyuni, S. (2018). IFRS convergence investigation: Corporate social responsibility disclosure in relation to good corporate governance and corporate size. PEOPLE: International Journal of Social Sciences, 4(2), 531-546. https://doi.org/10.20319/pijss.2018.42.531546

Suryani, A. W., \& Rofida, E. (2020). Environmental accounting from the new institutional sociology theory lens: branding or responsibility? Jurnal Dinamika Akuntansi Dan Bisnis, 7(2), 189-204. https://doi.org/10.24815/jdab.v7i2.17126

Suttipun, M., \& Stanton, P. (2012). A study of environmental disclosures by Thai listed companies on websites. Procedia Economics and Finance, 2(Af), 9-15. https://doi.org/10.1016/s2212-5671(12)00059-7

Syabilla, D., Wijayanti, A., \& Fahria, R. (2021). Pengaruh investasi hijau dan keragaman dewan direksi terhadap pengungkapan emisi karbon. Konferensi Riset Nasional Ekonomi, Manajemen, Dan Akuntansi, 2, 1171-1186.

Walhi. (2017). Indah kiat pulp and paper sumber kerusakan lingkungan. In Siaran Pers Wahana Lingkungan Hidup Indonesia (Walhi). https://www.walhi.or.id/indah-kiat-pulp-papersumber-kerusakan-lingkungan

Welbeck, E. E., Owusu, G. M. Y., Bekoe, R. A., \& Kusi, J. A. (2017). Determinants of environmental disclosures of listed firms in Ghana. International Journal of Corporate Social Responsibility, 2(1). https://doi.org/10.1186/s40991-017-0023-y

Wu, H., \& Shen, X. (2010). Environmental disclosure, environmental performance and firm value. 2010 International Conference on E-Product E-Service and E-Entertainment, ICEEE2010, November 2010, 1-6. https://doi.org/10.1109/ICEEE.2010.5661447

Wut, T. M., \& Ip, W. E. (2021). Assessment framework of corporate social responsibility 
Owner: Riset \& Jurnal Akuntansi

e-ISSN : 2548-9224 |p-ISSN : 2548-7507

Volume 6 Nomor 1, Januari 2022

DOI : https://doi.org/10.33395/owner.v6i1.542

disclosure. International Journal of Innovation, Creativity and Change, 15(6), 311-326.

Yusoff, H., Kamaruddin, S. H., \& Ghani, E. K. (2018). Environmental reporting practices of top public listed companies: analyzing pre-post corporate social responsibility framework. Indonesian Journal of Sustainability Accounting and Management, 2(1), 50. https://doi.org/10.28992/ijsam.v2i1.48 